\title{
REPLY TO COMMENTS
}

\author{
Anders Gustafsson \& Håkan Karlsson
}

We appreciate the valuable comments on our article presented by our colleagues and we would also like to thank the editors of CSA for the possibility to bring forward the important discussion concerning the relationship between archaeology, cultural heritage and politics. It is obvious that the discussion concerning the future strategy of Swedish archaeology in defence of a solidarist and multicultural society within the framework of the contemporary political situation has much to learn from experiences derived from international contexts where there has been - and in some cases still is - a more clear-cut and visible link between archaeology and politics, and where archaeologists and cultural heritage managers have been forced to handle the rhetorical use of archaeology and cultural heritage by various xenophobic and/or racist political parties.

In this context the Danish situation as presented by Mette Bjerrum Jensen in her comment is highly interesting. It seems as if the Swedish situation is very much a parallel to the Danish one and that the most important difference is that the development in Denmark lies about one decade ahead of the development in Sweden. According to Bjerrum Jensen it seems as if many Danish archaeologists, during the last decade, have acted quite passively and hoped for a changed political agenda in the elections, but that this strategy has backfired. This is because the xenophobic tendencies have grown stronger in the Danish society, not least as a consequence of a political agenda that has weakened the influence of the human sciences. At the same time, most Danish archaeologists - trained in the traditional craft of archaeology and unaccustomed 
to reflecting critically on the political dimensions of archaeology and cultural heritage - have quite easily adjusted to the existing (right-wing) political agenda. Thus, from our point of view it is clear that an active strategy is needed in the Swedish case if Swedish archaeology is to avoid meeting the same fate in the near future. One advantage in the Swedish context is that the Sweden Democrats' rhetorical use of the past and cultural heritage for their xenophobic politics is a rather new phenomenon and that it therefore can be discussed and questioned right from the start. The practical "case studies" presented by Bjerrum Jensen in the form of dilemmas are also interesting since they show us how hard it can be to decide what to consider as right or wrong and how to act practically and politically in specific situations. This practical, down to earth perspective - which we think is excellent - comes forth also in Bjerrum Jensen's statement that the 'guidelines' we present in our article ought to be more specific. That is absolutely right, but as presented in the article these guidelines are to be viewed more as a first step and as a background to further discussions.

In her comment Kerstin Cassel points out that she is not convinced by our conclusion that it is the research councils and foundations that are the key to the problem. Nor are we, since we have not pointed out these organizations as the key to the problem but rather as a part of the problematic situation. This is because the neglect - as we show in our keynote text - of this research has weakened Swedish archaeology and its possibilities to handle the current political situation. In this context it ought to be pointed out that one of the authors of this text is also a member of one of the Swedish Research Council's evaluation panels, but that this fact cannot prevent a critical reflection of the problematic situation. Needless to say, this means that not all members of these research councils and foundations are conservative and traditionalist archaeologists. Perhaps our rhetoric is generalizing, but despite this we still mean that the difficulties of these organizations to support research on the topics discussed here have weakened Swedish archaeology in this particular case. Cassel also stresses that we present a simplified polarization between traditional/empirical research on the one hand and a research that has an awareness of the political dimensions on the other. Perhaps our polarization is simplified in order to justify the important discussions we put forward, but at the same time one cannot deny the differences between these standpoints and their advocates, and that there exist clear problems among a number of more traditional archaeologists with regard to handling the political implications of archaeology as well as accepting the existence of different archaeologies. In her examples Cassel points out that projects and ideas with well-intended aims and 
ambitions always run the risk of creating misunderstandings as well as opposite effects if they are not well formulated and expressed. This is correct, and in one of the examples that Cassel lifts forward, the project Agenda Cultural Heritage (Sw. Agenda kulturarv), this is obvious. We are very positive to the project and its ambitions, but some of the critical points that Cassel stresses are correct and probably due to the unfortunate fact that the project was carried out quite hastily. Cassel's second example approaches parts of the present DNA-research within Swedish archaeology and we fully support her thought-provoking argumentation. She is completely right when stating that this research contains huge risks since in certain ways it has frightening similarities with older discussions concerning blood and race. At the same time, although it is not the intention, the project discussed runs the risk of supporting various xenophobic and racist arguments. This is interesting because it shows that also within archaeology's natural scientific directions, which are often presented as totally non-political, there is an existing risk. These examples underline Cassel's argument concerning the importance of being well formulated and expressed and that it is of crucial importance how archaeology is presented and formulated. For us this stresses the fact that one ought to be well prepared both tactically and strategically when launching an archaeological criticism of the use of the past and cultural heritage by xenophobic political parties. Undoubtedly, one ground for such preparation is more research on the support research concerning the relationship between archaeology, cultural heritage and politics.

The comments presented by Nick Shepherd are important in a number of ways, not least since they are put forward from a South African context where narrations of the past and the cultural heritage until a few decades ago were actively used in the racist oppression of certain groups in the society. Shepherd stresses rightly the similarities between the arguments of the apartheid rhetoric and those advocated by SD, but he also presents us with very interesting insights concerning how South African archaeologists during the I970s and I980s indirectly came to support apartheid as a consequence of their avoidance of politics. The standard formulation that archaeology has nothing to do with politics led to a situation where archaeology came to be a cooperative part of racist politics. This is really something worth noticing for Swedish archaeologists who today seem to present the same standard argument, and who try to avoid the political dimensions of archaeology and cultural heritage by hiding behind scientific arguments. Shepherd's reasoning concerning the relationship between the current international and disparate trends of economic liberalization and cultural globaliza- 
tion on the one hand and xenophobia, Islamophobia and racism on the other hand is highly interesting since it widens the discussion of the role of archaeology and cultural heritage in general, at the same time as it contextualizes our Swedish example on a global level. We can just support Shepherd's arguments, and the question is whether archaeology in the future shall continue to support nations with security in the form of identity creation on different levels, or if the discipline instead should contribute with critical and reflective discussions and narrations. This question is perhaps also a question of our ability and strength to challenge our own security and our own spectres.

In the comments by Laurjane Smith and Emma Waterton as well, the current Swedish situation is contextualized in an interesting manner and in a broader international context. Here, however, it is interesting to conclude that the Swedish situation is brand new if compared with the more mature use of cultural heritage in the ultra-right argumentation in various parts of Europe and Australia. Undoubtedly, this promotes Swedish archaeology with the advantage of a number of good lessons and ideas concerning how it can handle the situation in the future. Smiths \& Waterton's reasoning concerning the situation in Australia is extra valuable, since their experiences of what they call the 'Australian history wars' show the importance of publicly debating disciplinary ideas and knowledge in all arenas of society. Thus, they mean that the public debate and open challenging of the ultra-right positions on cultural heritage are crucial if the desire is to avoid a situation where these ideas become assimilated as legitimate and reasonable policies. It is also stressed that the public debate is important on a general level when it comes to raising public understanding about the political nature of the interpretations of the cultural heritage and the past. We totally agree with these arguments presented by Smith and Waterton, and in our 'guidelines' the open and public discussion about the actual issues ought to be more central. A trajectory runs throughout their comments which we find very valuable, namely the focus on the importance of practical and concrete work with the public. In line with Nancy Fraser's works, Smith and Waterton also stress the need to view cultural heritage as a political resource and that the public's participation in the work with it and in the use of it is crucial for the hindrance of xenophobia as well as for a sustainable social development of society. We can only agree, and Fraser's argumentation has much in common with the intentions and ideas inherent in the project Agenda Cultural Heritage ( $S w$. Agenda kulturarv), which may have some shortcomings but in our opinion is nonetheless a fruitful path for the future of Swedish archaeology and cultural heritage management. 
In conclusion it can be stated that all commentators are positive to the fact that we have chosen to open up the actual discussion. They also present a number of interesting and valuable examples that deepen different aspects of the current problem. It is our hope that this important discussion does not stop here, but rather that it can constitute the point of departure for a common and practical strategic and future-directed work. This work ought to take place within Swedish and international archaeology as well as the cultural heritage management sector with the aim of challenging the xenophobia - which at the moment is spreading like a cancerous tumor in Sweden and in other parts of the world - while at the same time standing up for a solidarist and multicultural society. This work ought to be of interest despite how we view the political dimensions of archaeology, and perhaps our 'guidelines', together with the valuable comments and complements presented by the commentators, can be a first step. 